\title{
Parâmetros microbiológicos e físico-químicos durante a produção e maturação do queijo Fascal
}

\author{
Microbiological and physicochemical parameters \\ during the production and ripening of Fascal cheese
}

Cássia Regina Nespolo, Jaslin Alexandra Settin Taffarel \& Adriano Brandelli

\begin{abstract}
RESUMO
A produção de produtos lácteos de ovelha pode proporcionar uma alternativa rentável em relação aos produtos de leite bovino, devido ao sabor e à textura específicos. Leites ovino e caprino podem ser utilizados em diferentes aplicações e têm-se tornado um meio muito importante para a economia em distintas regiões geográficas. O objetivo deste trabalho foi avaliar a qualidade do leite de ovelha e do queijo Fascal produzido na região metropolitana de Porto Alegre, RS. As amostras de queijo foram analisadas no $1^{\circ}, 30^{\circ}, 60^{\circ} \mathrm{e} 90^{\circ}$ dias de maturação, para verificar possíveis alterações nos parâmetros microbiológicos e físico-químicos. Estas amostras foram mantidas em câmara refrigerada durante o período de maturação. Os resultados indicaram ausência de Salmonella spp. em todas as amostras analisadas. As contagens de aeróbios mesófilos, estafilococos coagulase positiva, coliformes totais e coliformes fecais demonstraram resultados considerados aceitáveis, de acordo com a legislação brasileira para leite cru e para produtos lácteos. Os parâmetros físico-químicos do leite ovino apresentaram valores semelhantes aos encontrados em amostras de leite de ovelha provenientes do sul do Brasil. Em função dos resultados, concluiu-se que as características físico-químicas do queijo foram modificadas durante a maturação, com diminuição no conteúdo de umidade e aumento nos teores de proteína e gordura. O produto final foi classificado como um queijo gordo e de baixa umidade.
\end{abstract}

Descritores: queijo, leite de ovelha, maturação, avaliação da qualidade.

\begin{abstract}
Production of dairy products from ewes can provide a profitable alternative to cow milk products owing to their specific taste and texture. Sheep and goat milks can be used for different purposes and has become a very important mean for the economy in different geographical areas. The main objective of this study was to evaluate the quality of ewe milk and Fascal cheese produced in the metropolitan area of Porto Alegre, RS, Brazil. Cheese samples were analyzed in the $1^{\text {st }}, 30^{\text {th }}, 60^{\text {th }}$ and $90^{\text {th }}$ days to detect possible microbiological and physicochemical changes. They were kept refrigerated during ripening. The results indicated the absence of Salmonella spp. in all the samples evaluated. The counts of aerobic mesophilic, coagulasepositive staphylococci, total coliforms and faecal coliforms conformed to the Brazilian official requirements for raw ovine milk and dairy products. The physicochemical parameters showed that in general the ovine milk analyzed had similar values to those observed in the south of Brazil. According to the results, it was concluded that the physicochemical characteristics of the cheese were altered during ripening, showing moisture losses and a rise in the concentrations of protein and fat. The final product was classified as a cheese with high fat content and low moisture.
\end{abstract}

Keywords: cheese, ovine milk, ripening, quality evaluation.

${ }^{1}$ Laboratório de Bioquímica e Microbiologia Aplicada, Instituto de Ciência e Tecnologia de Alimentos, Universidade Federal do Rio Grande do Sul (UFRGS), Av. Bento Gonçalves 9500, 91501-970 Porto Alegre, Brasil. CORRESPONDÊNCIA: A. Brandelli [abrand@ufrgs.br - Fax: +55 (51) 3308 7048]. 


\section{INTRODUÇÃO}

O rebanho ovino é o quarto no Brasil e o Rio Grande do Sul é o principal produtor [11]. O leite de ovelha corresponde a 1,3\% da produção mundial [7], com destaque para a produção de queijos finos na Europa [20]. No Brasil, os primeiros ovinos da raça Lacaune foram introduzidos em 1992 e estão bem adaptados às condições de clima e alimentação do sul do país, com produção de leite média diária de 1,3 L por ovelha [2]. O leite de ovelha é uma matériaprima com valores de proteína, gordura, cinzas e densidade maiores, em comparação ao leite bovino [19].

A produção de queijos com leite não submetido ao tratamento térmico é permitida pela legislação brasileira, desde que o período de maturação seja maior que 60 dias [12]. O leite de ovelha cru contém um número muito maior de cepas diversas [5] e constitui boa fonte de bactérias lácticas, que desempenham importante papel na fermentação e nas características sensoriais dos produtos lácteos [6]. Por outro lado, a utilização do leite cru pode favorecer patógenos contaminantes, como coliformes termotolerantes e Escherichia coli [3], e levar a surtos associados com estafilococos nestes produtos [1].

A criação de ovelhas para produção de leite e de queijos no RS despertou o interesse no acompanhamento ao longo das etapas de fabricação do queijo Fascal. Este produto é o primeiro desenvolvido no Brasil, produzido com leite cru de ovelha da raça Lacaune e comercializado no mercado regional. $\mathrm{O}$ presente estudo foi realizado durante a produção do queijo Fascal e ao longo de seu período de maturação, com o objetivo de avaliar parâmetros físico-químicos e microbiológicos e classificar o produto final, com base nos parâmetros estabelecidos na legislação vigente para queijos.

\section{MATERIAIS E MÉTODOS}

\section{Material}

O trabalho foi realizado em uma indústria de laticínios no município de Viamão/RS, que processa leite produzido por ovelhas da raça Lacaune. O município participa com $35,7 \%$ do rebanho ovino e com $21,2 \%$ da produção de leite microrregional [11]. Foram coletadas amostras do leite cru de ovelha, antes de iniciar a produção do queijo, e amostras do queijo Fascal durante a produção e ao longo do período de maturação, até obtenção de um produto maturado por noventa dias. No total, foram feitas quatro coletas: coleta $1\left(1^{\circ} \mathrm{dia}\right)$, coleta $2\left(30^{\circ} \mathrm{dia}\right)$, coleta $3\left(60^{\circ} \mathrm{dia}\right)$ e coleta $4\left(90^{\circ}\right.$ dia). O queijo foi obtido de acordo com o protocolo de produção adotado pela indústria, utilizando leite de ovelha cru, adição de acidificante e de cultura iniciadora comercial, com maturação em câmara refrigerada a $10^{\circ} \mathrm{C}$. A indústria seguiu os procedimentos de boas práticas de fabricação, desde a ordenha até a obtenção do produto final. As amostras foram colocadas em embalagens estéreis, identificadas e transportadas em condições refrigeradas até o Instituto de Ciência e Tecnologia de Alimentos (ICTA)/UFRGS, onde foram realizadas todas as análises microbiológicas e físico-químicas.

\section{Análises microbiológicas}

As análises foram selecionadas com base nas análises microbiológicas exigidas pela legislação brasileira para leite cru e para queijos de baixa umidade $[12,14,17]$. Foram realizadas as análises de coliformes a $30^{\circ} \mathrm{C}$, coliformes a $45^{\circ} \mathrm{C}$, estafilococos coagulase positiva, Salmonella spp. e Contagem Padrão em Placas. As metodologias seguiram os procedimentos descritos nos "Métodos Analíticos Oficiais para Análises Microbiológicas para Controle de Produtos de Origem Animal e Água" [15].

\section{Análises físico-químicas}

Foram avaliados os seguintes parâmetros físicoquímicos: umidade, gordura, proteína, cinzas, carboidratos, acidez e densidade. A proteína foi avaliada pelo método de Kjeldahl (fator de conversão 6,38). A determinação do teor de umidade foi feita pela secagem até obtenção de peso constante. A determinação do teor de gordura ou matéria gorda foi realizada com o auxílio de butirômetro de Gerber ${ }^{1}$, em amostras de leite, ou através do método de Soxhlet. $\mathrm{O}$ teor de glicídios redutores em lactose foi obtido através do método de LaneEynon. Todas as metodologias seguiram os Métodos Analíticos Oficiais Físico-Químicos, para Controle de Leite e Produtos Lácteos [16]. A determinação do índice de acidez titulável foi expressa em ácido lático e a leitura de densidade foi feita em termolactodensímetro ${ }^{2}$ a $15^{\circ} \mathrm{C}[10]$. As análises foram realizadas em triplicata.

\section{Análise estatística}

Os dados obtidos nas análises físico-químicas foram avaliados através da análise de variância, complementado com o teste de comparações múltiplas de Student-Newmann-Keuls. As diferenças foram consideradas estatisticamente significativas para $p<0,05$. 


\section{RESULTADOS}

\section{Análises microbiológicas}

Os resultados verificados no leite de ovelha cru, utilizado para o preparo do queijo analisado, indicaram o valor de $5,0 \times 10^{4} \mathrm{UFC} / \mathrm{mL}$ para Contagem Padrão em Placas. Os demais resultados foram ausência de Salmonella sp. em $25 \mathrm{ml}$ e $3,3 \times 10^{3} \mathrm{UFC} / \mathrm{mL}$ para estafilococos coagulase positiva. Para coliformes a $30^{\circ} \mathrm{C}$ e Coliformes a $45^{\circ} \mathrm{C}$, os valores foram de $2,2 \times 10^{2} \mathrm{NMP} / \mathrm{ml}$ e $1,1 \times 10^{2} \mathrm{NMP} / \mathrm{mL}$, respectivamente.

As avaliações microbiológicas no queijo Fascal foram realizadas mensalmente, a partir do momento da fabricação até o período final da maturação. A primeira coleta foi realizada na massa coalhada colocada na forma e após completar o tempo de prensagem padrão para este queijo. Os resultados das coletas são apresentados na Tabela 1.

\section{Análises físico-químicas}

Os valores médios dos parâmetros físico-químicos do leite cru e nos diferentes tempos de maturação do queijo de leite de ovelha estão expressos na Tabela 2. Além dos resultados para leite ovino cru apresentados na Tabela 2, foram ainda obtidos o valor médio de densidade a $15^{\circ} \mathrm{C}$ de $1,037 \mathrm{~g} / \mathrm{mL}$ e o valor médio de acidez de $0,15 \mathrm{~g}$ de ácido lático por $100 \mathrm{~mL}$ de leite.

Os valores médios para umidade, proteína, gordura, cinzas e glicídios, no queijo Fascal recém-produzido e ao longo de seu período de maturação, estão apresentados Tabela 2. O conteúdo de umidade do queijo, ao final de noventa dias de maturação, foi de $32,14 \%$. Desta forma, foi classificado como queijo de baixa umidade, geralmente conhecido como queijo de massa dura. No cálculo do teor de gordura no extrato seco, o valor obtido foi de $54,92 \%$, classificando-o como um queijo gordo [12].

Tabela 1. Análises microbiológicas realizadas no queijo Fascal ao longo do período de maturação.

\begin{tabular}{|c|c|c|c|c|c|}
\hline Análise Microbiológica & Queijo (1 dia) & Queijo (30 ${ }^{\circ}$ dia) & Queijo (60 dia) & Queijo (90 dia) & Padrão \\
\hline Coliformes a $30^{\circ} \mathrm{C}(\mathrm{NMP} / \mathrm{g})$ & $2,8 \times 10^{2}$ & $8,0 \times 10^{1}$ & $2,6 \times 10^{1}$ & $1,4 \times 10^{1}$ & $1,0 \times 10^{3}$ (a) \\
\hline Coliformes a $45^{\circ} \mathrm{C}(\mathrm{NMP} / \mathrm{g})$ & $1,1 \times 10^{2}$ & $4,6 \times 10^{1}$ & 0,9 & $<0,3$ & $5,0 \times 10^{2(a, b)}$ \\
\hline $\begin{array}{l}\text { Estafilococos coagulase } \\
\text { positiva (UFC/g) }\end{array}$ & $2,5 \times 10^{3}$ & $2,8 \times 104$ & $2,4 \times 10^{3}$ & $8,0 \times 10^{2}$ & $1,0 \times 10^{3}(\mathrm{a}, \mathrm{b})$ \\
\hline Salmonella sp. (em 25g) & Ausente & Ausente & Ausente & Ausente & Ausente $^{(\mathrm{a}, \mathrm{b})}$ \\
\hline
\end{tabular}

As amostras foram avaliadas segundo metodologia oficial para análises microbiológicas para controle de produtos de origem animal [15]. a'Limites máximos para Queijo de Baixa Umidade [12]; 'Limites máximos para Queijo de Baixa Umidade [17].

Tabela 2. Análises físico-químicas realizadas no leite de ovelha cru e no queijo Fascal, ao longo do período de maturação.

\begin{tabular}{cccccc}
\hline $\begin{array}{c}\text { Análise Físico- } \\
\text { Química }\end{array}$ & $\begin{array}{c}\text { Leite de Ovelha } \\
\text { Cru }\end{array}$ & Queijo (1 $\mathbf{1}^{\circ}$ dia) & Queijo (30 dia) & Queijo (60 $\left.\mathbf{~ d i a}^{\circ}\right)$ & Queijo (90 $^{\circ}$ dia) \\
\hline Umidade (g/100g) & $82,55 \pm 0,51$ & $57,33 \pm 3,66^{\mathrm{a}}$ & $46,07 \pm 3,60^{\mathrm{b}}$ & $40,34 \pm 2,07^{\mathrm{b}, \mathrm{c}}$ & $32,14 \pm 1,17^{\mathrm{c}}$ \\
Proteína (g/100g) & $5,52 \pm 0,09$ & $14,42 \pm 1,27^{\mathrm{a}}$ & $19,71 \pm 1,30^{\mathrm{b}}$ & $19,15 \pm 1,31^{\mathrm{b}}$ & $24,55 \pm 0,94^{\mathrm{c}}$ \\
Gordura (g/100g) & $6,47 \pm 0,36$ & $23,00 \pm 1,71^{\mathrm{a}}$ & $26,33 \pm 2,08^{\mathrm{a}}$ & $33,56 \pm 1,82^{\mathrm{b}}$ & $37,27 \pm 1,11^{\mathrm{b}}$ \\
Cinzas (g/100g) & $0,70 \pm 0,03$ & $2,33 \pm 0,58^{\mathrm{a}}$ & $3,19 \pm 0,32^{\mathrm{a}}$ & $3,66 \pm 0,57^{\mathrm{a}}$ & $3,62 \pm 0,61^{\mathrm{a}}$ \\
& & & & \\
Carboidratos (g/100g) & $4,41 \pm 0,13$ & $1,21 \pm 0,16^{\mathrm{a}}$ & $2,18 \pm 0,45^{\mathrm{a}}$ & $1,92 \pm 0,20^{\mathrm{a}}$ & $1,35 \pm 0,03^{\mathrm{a}}$ \\
\hline
\end{tabular}

As amostras foram avaliadas segundo métodos oficiais físico-químicos para controle de leite e produtos lácteos [16]. Os resultados são expressos como média \pm erro padrão da média; médias na mesma linha, seguidas por letras iguais, não diferem significativamente $(p<0,05)$. 


\section{DISCUSSÃO}

Os resultados das avaliações microbiológicas e físico-químicas realizadas no leite de ovelha cru foram comparados com os padrões contidos no Regulamento Técnico de Identidade e Qualidade de Leite Cru Refrigerado [14]. Para o queijo produzido com leite de ovelha cru, foram utilizados o Regulamento Técnico de Identidade e Qualidade de Queijos [12] e Regulamento Técnico sobre os Padrões Microbiológicos para Alimentos [17].

O valor observado para a Contagem Padrão em Placas indicou alta contagem de micro-organismos aeróbios mesófilos, porém não superior ao permitido

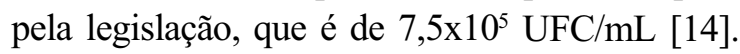

A avaliação de Salmonella spp. em queijos indicou que as amostras estavam de acordo com o que está estabelecido na legislação brasileira. Uma revisão sobre queijos de leite ovino demonstrou que não houve detecção de Salmonella spp. em queijos Castelo Branco e Idiazábal, ambos produzidos com leite cru de ovelha, sendo que Salmonella arizonae foi a única espécie detectada ao longo do tempo de maturação do queijo La Serena [9].

Os resultados obtidos para Coliformes a $30^{\circ} \mathrm{C}$ e Coliformes a $45^{\circ} \mathrm{C}$ indicaram que a contaminação por estes grupos manteve-se abaixo dos níveis máximos permitidos pela legislação brasileira para queijos de baixa umidade. Resultados encontrados na literatura apresentam uma quantificação de coliformes totais e Escherichia coli em queijo Serpa acima de $2,5 \times 10^{6} \mathrm{UFC} / \mathrm{g}$ e $1,4 \times 10^{3} \mathrm{UFC} / \mathrm{g}$, respectivamente, com presença também em queijo Serra da Estrela [9]. Foi observada a diminuição gradual nos níveis de Coliformes a $30^{\circ} \mathrm{C}$ e Coliformes a $45^{\circ} \mathrm{C}$, ao longo da maturação do queijo. Um estudo com queijo de leite de ovelha observou contaminações altas por coliformes fecais e E. coli no início do período de maturação, sendo que esta não foi quantificada ao final deste [3].

Dentre os parâmetros analisados neste trabalho, a contagem de estafilococos coagulase positiva foi o que demonstrou resultados preocupantes até a Coleta 3. O valor observado nesta coleta foi acima do máximo permitido pela legislação, verificando-se valores aceitáveis no queijo maturado por 90 dias, mesmo sendo permitida sua comercialização a partir de 60 dias de maturação. Em amostras de queijos produzidos com leite de ovelha na Europa, denominados Castelo Branco e Idiazábal, não foi detectada a presença de $S$. aureus.
Já para queijo Serpa, alguns autores não detectaram a presença de $S$. aureus, resultado contrário obtido por outros que quantificaram acima de $2 \times 10^{3} \mathrm{UFC} / \mathrm{g}$ no mesmo tipo de queijo [9]. Nas amostras avaliadas, observou-se um aumento inicial nas contagens de estafilococos coagulase positiva da primeira para a segunda coleta, seguida por uma diminuição gradual até o final da maturação. Salienta-se que o produto final apresentou contagens abaixo do máximo permitido pela legislação brasileira.

Conforme ressaltado anteriormente, foram utilizadas bactérias lácticas iniciadoras comerciais na fabricação deste queijo. Além de desenvolverem uma rota essencial na produção de laticínios, esses micro-organismos contribuem para a qualidade do produto [18]. Sua capacidade de produzir ácido láctico a partir da lactose auxilia na redução do $\mathrm{pH}$, o que provoca a expulsão de soro da coalhada, diminuição do conteúdo de umidade e do risco de deterioração microbiológica. Durante a maturação do queijo, micro-organismos patogênicos são normalmente inibidos por bactérias lácticas [3], devido à produção dos ácidos láctico e acético e de uma ampla variedade de metabólitos antimicrobianos [3,18]. Aliado ao uso de bactérias starter, a própria utilização do leite cru contribui para o aumento na contagem de bactérias lácticas no queijo e para que ocorra a superação da microbiota patogênica pela microbiota benéfica na produção do queijo, desenvolvimento de sabor e características de qualidade no produto final.

O queijo produzido com leite de ovelha apresentou variações nas contagens microbiológicas ao longo do período de produção e de maturação, demonstrando que os valores para coliformes a $30^{\circ} \mathrm{C}$, Coliformes a $45^{\circ} \mathrm{C}$ e estafilococos coagulase positiva diminuem durante o tempo de maturação, atingindo os menores valores ao final de noventa dias. Considerando a diminuição observada ao longo da maturação e a ausência de Salmonella spp. em todas as coletas, bem como os limites estabelecidos para o produto, pode-se concluir que o produto final apresentou qualidade microbiológica adequada.

Considerando os valores de densidade, a acidez, a gordura, a proteína e o cálculo de extrato seco desengordurado, observou-se que o leite utilizado para a produção do queijo estava dentro dos requisitos físicos e químicos estabelecidos para leite cru refrigerado [14]. Deve-se levar em conta que esses limites são estabelecidos 
para leite bovino, sendo que já existe legislação específica para leite caprino [13].

Os valores observados nos parâmetros físicoquímicos para o leite de ovelha cru foram semelhantes aos descritos nas amostras do período de lactação de 140 dias, e inferiores nos tempos de lactação de 7, 30 ou 60 dias, para ovelhas da mesma raça Lacaune na região da serra gaúcha [2]. A densidade apresentou valores semelhantes, entre 1,035 e $1,038 \mathrm{~g} / \mathrm{mL}$, e o teor de lactose foi superior em todos os períodos de lactação, com um máximo de $5,04 \%$. Os resultados obtidos para leite de ovelhas da raça Corriedale, demonstraram teores de gordura bem inferiores em todas as semanas de lactação estudadas, com percentual médio de 3,5\%, e um valor médio semelhante para densidade de $1,036 \mathrm{~g} / \mathrm{mL}[21]$.

Os valores descritos em uma revisão para leite ovino indicaram um percentual médio para gordura de $7,9 \%$, proteína de $6,2 \%$, cinzas de $0,9 \%$, lactose de 4,9\% [19], todos superiores aos listados na Tabela 2. $\mathrm{O}$ valor de acidez em ácido láctico varia entre $0,22 \mathrm{e}$ $0,25 \%$, também superior ao observado no leite ovino analisado [19].

O conteúdo de umidade de $32,14 \%$, quantificado ao final do período de maturação do queijo analisado, pode ser comparado com o valor observado em queijo ovino Piacentinu Ennese, com maturação entre 60 e 120 dias [8]. Uma comparação com nove queijos italianos produzidos com leite de ovelha apresentou valores médios de umidade superiores ao do queijo em estudo, com variações entre 35 e 38,2\% [4]. Em um estudo com queijos de leite de ovelha produzidos em Portugal e Espanha, a maioria dos queijos apresentou valores de umidade superiores, com exceção do queijo de Évora e do Idiazábal maturado por 180 dias [9].

$\mathrm{O}$ teor médio de proteína no queijo maturado foi inferior ao de $26,83 \%$ observado aos 60 dias de maturação do queijo Piacentinu Ennese [8]. Valores superiores para proteína também foram observados em nove queijos ovinos italianos analisados [4], bem como em queijos da Península Ibérica [9].
O conteúdo de gordura no extrato seco de $54,92 \%$ foi superior aos observados em todos os períodos de maturação do queijo Piacentinu Ennese [8]. Os teores médios de gordura em queijos italianos variaram entre 27,5 e $29,5 \%$ [4], valores inferiores ao observado ao final da maturação do queijo em estudo, que foi de $37,27 \%$. Já os queijos ovinos portugueses e espanhóis apresentaram valores superiores, compreendidos entre 43 e $59,83 \%$ [9].

Os resultados das análises físico-químicas permitiram a classificação do queijo maturado, de acordo com o conteúdo de umidade e de matéria gorda no extrato seco [12].

\section{CONCLUSÕES}

O queijo e o leite de ovelha analisados neste estudo apresentaram os resultados dentro dos limites microbiológicos estabelecidos pela legislação brasileira para estes tipos de alimentos. A avaliação físicoquímica do leite indicou que a composição nutricional foi semelhante à de leite ovino produzido no Brasil, mas inferior à de leite ovino produzido no continente europeu. Os valores indicaram que o leite cru ovino possuía a composição nutricional mínima exigida pela legislação brasileira, porém os limites utilizados para comparação são específicos para leite bovino. Os resultados físico-químicos observados no queijo indicaram, conforme esperado, a perda de umidade ao longo da maturação, concentração de proteínas e alto teor de gordura ao final da maturação. O queijo de leite de ovelha maturado por um período de noventa dias foi classificado pelo Regulamento Técnico de Identidade e Qualidade de Queijos como um produto de baixa umidade ou de massa dura e gordo, em função do conteúdo de gordura no extrato seco.

Agradecimentos. Este trabalho recebeu suporte financeiro da CAPES-CDBA e do CNPq.

\section{NOTAS INFORMATIVAS}

${ }^{1}$ Butirômetro de Gerber, Zeiss-Jena, Jena, Alemanha.

${ }^{2}$ Termolactodensímetro, Incoterm, Porto Alegre, RS, Brasil.

\section{REFERÊNCIAS}

1 Arqués J.L., Rodríguez E., Gaya P., Medina M., Guamis B. \& Nuñez M. 2005. Inactivation of Staphylococcus aureus in raw milk cheese by combinations of high-pressure treatments and bacteriocin-producing lactic acid bacteria. Journal of Applied Microbiology. 98: 254-260.

2 Brito M.A., González F.D., Ribeiro L.A., Campos R., Lacerda L., Barbosa P.R. \& Bergmann G. 2006. Composição do sangue e do leite em ovinos leiteiros do sul do Brasil: variações na gestação e na lactação. Ciência Rural. 36: $942-948$. 
3 Caridi A. 2003. Identification and first characterization of lactic acid bacteria isolated from de artisanal ovine cheese Pecorino del Poro. International Journal of Dairy Technology. 56: 105-110.

4 Coda R., Brechany E., De Angelis M., De Candia S., Di Cagno R. \& Gobbetti M. 2006. Comparison of the Compositional, Microbiological, Biochemical, and Volatile Profile Characteristics of Nine Italian Ewes' Milk Cheeses. Journal of Dairy Science. 89: 4126-4143.

5 De Angelis M., Corsetti A., Tosti N., Rossi J., Corbo M.R. \& Gobbetti M. 2001. Characterization of non-starter lactic acid bacteria from Italian ewe cheeses based on phenotypic, genotypic, and cell wall protein analyses. Applied and Environmental Microbiology. 67: 2011-2020.

6 Deegan L.H., Cotter P.D., Hill C. \& Ross P. 2006. Bacteriocins: biological tool for bio-preservation and shelf-life extension. International Dairy Journal. 16: 1058-1071.

7 Empresa Brasileira de Pesquisa Agropecuária (EMBRAPA). 2005. Embrapa Gado de Leite: Estatísticas. Disponível em: http://www.cnpgl.embrapa.br. Acesso em 12 maio 2005.

8 Fallico V., Tuminello L., Pediliggieri C., Horne J., Carpino S. \& Licitra G. 2006. Proteolysis and Microstructure of Piacentinu Ennese Cheese Made Using Different Farm Technologies. Journal of Dairy Science. 89: 37-48.

9 Freitas C. \& Malcata F.X. 2000. Microbiology and Biochemistry of Cheeses with Appélation d'Origine Protegeé and Manufactured in the Iberian Peninsula from Ovine and Caprine Milks. Journal of Dairy Science. 83: 584-602

10 Instituto Adolfo Lutz (IAL). 2006. Leite: Densidade a $15^{\circ} \mathrm{C}$. In: Normas analíticas do Instituto Adolfo Lutz: Métodos químicos e físicos para análise de alimentos. 4 ed. São Paulo: IMESP, pp.152-153.

11 Instituto Brasileiro de Geografia e Estatística (IBGE). 2006. Pesquisa da Pecuária Municipal 2006. Disponível em: http://www.ibge.gov.br. Acesso em: 20 ago. 2008.

12 Ministério da Agricultura Pecuária e Abastecimento (MAPA). 1996. Portaria №. 146, de 07/03/1996. D.O.U., Brasília, 11/03/1996. p.3977.

13 Ministério da Agricultura Pecuária e Abastecimento (MAPA). 2000. Instrução Normativa No. 37, de 31/10/2000.D.O.U., Brasília, 08/11/2000. p. 33.

14 Ministério da Agricultura Pecuária e Abastecimento (MAPA). 2002. Instrução Normativa No. 51, de 18/09/2002. D.O.U., Brasília, 20/09/2002. p.13.

15 Ministério da Agricultura Pecuária e Abastecimento (MAPA). 2003. Instrução Normativa No . 62, de 26/08/2003. D.O.U., Brasília, 18/09/2003. p.14.

16 Ministério da Agricultura Pecuária e Abastecimento (MAPA). 2006. Instrução Normativa No . 68, de 12/06/2006. D.O.U., Brasília, 14/12/2006, Seção 1, p. 8.

17 Ministério da Saúde. Agência Nacional de Vigilância Sanitária (MS). 2001. Resolução RDC No. 12, de 02/01/2001. D.O.U., Brasília, 02/01/2001. pp.1-54.

18 O'Sullivan L., Ross R.P. \& Hill C. 2002. Potential of bacteriocin-producing lactic acid bacteria for improvements in food safety and quality. Biochimie. 84: 593-604.

19 Park Y.W., Juárez M., Ramos M. \& Haenlein G.F.W. 2007. Physico-chemical characteristics of goat and sheep milk. Small Ruminant Research. 68: 88-113.

20 Prata L.F., Ribeiro A.C., Rezende K.T., Carvalho M.R.B., Ribeiro S.D.A. \& Costa R.G. 1998. Composição, perfil nitrogenado e características do leite caprino (Saanen). Ciência e Tecnologia de Alimentos. 18: 428-432.

21 Souza A.C.K.O., Osório M.T.M., Osório J.C.S., Oliveira N.M., Vaz C.M.S., Souza M. \& Corrêa G.F. 2005. Produção, composição química e características físicas do leite de ovinos da raça Corriedale. Revista Brasileira de Agrociência. 11: 73-77. 